URL: https://isr.phenikaa-uni.edu.vn/chitiet/thong-bao_2019_2_22_7_58_66/truyen-thong-quoc-te-sach-phenikaauni-tren-university-world-news

\title{
Truyền thông quốc tế: Sách Phenikaa Uni trên University World News
}

\author{
Nguyễn Thanh Huyền \\ Trung tâm ISR \\ Trường ĐH Phenikaa
}

Ngày 29 tháng 11 năm 2020

Cuối năm 2019, Trung tâm ISR chủ trì cuốn chuyên khảo The Vietnamese Social Sciences at a Fork in the Road (ISBN-13: 978-3110686074), do nhà xuất bản De Gruyter, CHLB Đức, phát hành (Imprint: Sciendo, De Gruyter Warsaw).

Chỉ vài tháng kể từ lúc sản phẩm ra đời, dịch bệnh COVID-19 cũng bùng phát toàn cầu. Ảnh hưởng tiêu cực đến đời sống nhiều mặt của thế giới, bao gồm cả giới khoa học và nghiên cứu. Lúc thông tin vaccine tiến triển tích cực hơn cũng là lúc tròn tuổi.

Trong hình bên dưới là ảnh bìa sách có ở trên hệ thống thương mại điện tử Amazon [1].

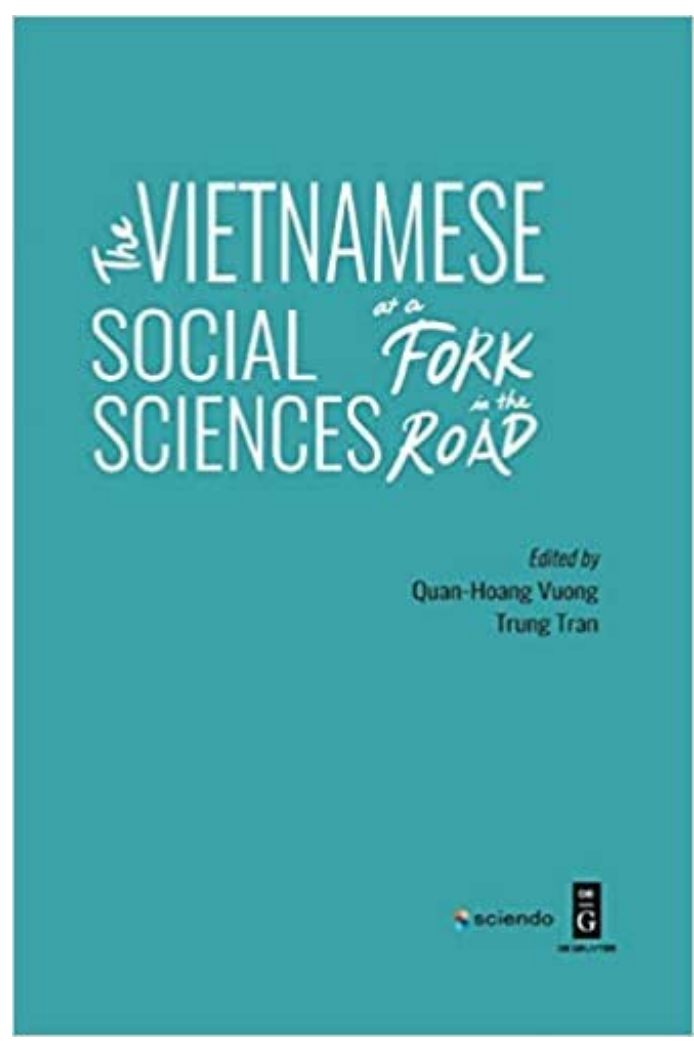

https://www.amazon.com/dp/3110686074 
Cuốn sách đã xuất hiện trong nhiều thư viện quốc tế. Dưới đây điểm mặt một số thư viện tiêu biểu đang lưu trữ sách (bản giấy và/hoặc điện tử).

\begin{tabular}{|c|c|c|c|}
\hline Thư viện & Loại & Quốc gia & OCLC / Internet \\
\hline $\begin{array}{l}\text { American Jewish } \\
\text { University }\end{array}$ & Đại học & Mỹ & OCLC queryString=bn:3110686082 \\
\hline $\begin{array}{l}\text { University of } \\
\text { Southampton }\end{array}$ & Đại học & Anh & https://www-lib.soton.ac.uk/ \\
\hline Cardiff University & Đại học & Anh & $\begin{array}{l}\text { https://whel-primo.hosted.exlibrisgroup.com/ } \\
\text { permalink/f/e82e5k/44CAR_ALMA511758652 } \\
10002420\end{array}$ \\
\hline $\begin{array}{l}\text { University of Bristol } \\
\text { Library }\end{array}$ & Đại học & Anh & OCLC \\
\hline ProQuest Libcentral & Thương mại & Toàn cầu & $\begin{array}{l}\text { https://public.ebookcentral.proquest.com; } \\
\text { Dewey: 309.1597; LCCN: HN700.5.A8 .V548 } \\
2019\end{array}$ \\
\hline $\begin{array}{l}\text { De La Salle College of } \\
\text { Saint Benilde }\end{array}$ & Đại học & Philippines & OCLC \\
\hline $\begin{array}{l}\text { Deutsche } \\
\text { Nationalbibliothek } \\
\text { Lepzig }\end{array}$ & $\begin{array}{l}\text { Thư viện } \\
\text { Quốc gia } \\
\text { (vùng) }\end{array}$ & Đức & http://d-nb.info/1197821848 \\
\hline $\begin{array}{l}\text { Franklin Pierce } \\
\text { University. DiPietro } \\
\text { Library }\end{array}$ & Đại học & Hoa Kỳ & OCLC \\
\hline $\begin{array}{l}\text { University of St } \\
\text { Andrews }\end{array}$ & Đại học & Anh & $\begin{array}{l}\text { https://library.st- } \\
\text { andrews.ac.uk/record=b3102560 S5 }\end{array}$ \\
\hline $\begin{array}{l}\text { Deutsche } \\
\text { Nationalbibliothek } \\
\text { Frankfurt am Main }\end{array}$ & $\begin{array}{l}\text { Thư viện } \\
\text { Quốc gia } \\
\text { (vùng) }\end{array}$ & Đức & http://d-nb.info/119894384X \\
\hline $\begin{array}{l}\text { Delft University of } \\
\text { Technology }\end{array}$ & Đại học & Hà Lan, Delft & OCLC \\
\hline $\begin{array}{l}\text { Universitätsbibliothek } \\
\text { Regensburg }\end{array}$ & Đại học & Đức & $\begin{array}{l}\text { https://www.regensburger- } \\
\text { katalog.de/TouchPoint/start.do?Query= } \\
\text { 1035\%3d\%22BV046678406\%22IN\%5b2\%5d }\end{array}$ \\
\hline $\begin{array}{l}\text { Erikson Institute. } \\
\text { Edward Neisser Library }\end{array}$ & $\begin{array}{l}\text { Thư viện } \\
\text { công }\end{array}$ & Mỹ, Chicago & OCLC \\
\hline $\begin{array}{l}\text { Oklahoma City } \\
\text { University Law Library }\end{array}$ & Đại học & $\begin{array}{l}\text { Mỹ, } \\
\text { Oklahoma }\end{array}$ & OCLC \\
\hline $\begin{array}{l}\text { Johnson \& Wales } \\
\text { University, Charlotte } \\
\text { Library }\end{array}$ & Đại học & $\begin{array}{l}\text { Mỹ, North } \\
\text { Carolina }\end{array}$ & OCLC \\
\hline $\begin{array}{l}\text { Cégep et Université du } \\
\text { Québec en Abitibi- } \\
\text { Témiscamingue } \\
\text { Sandbox }\end{array}$ & Đại học & $\begin{array}{l}\text { Canada, } \\
\text { Québec }\end{array}$ & $\begin{array}{l}\text { 425, Boul. Du Collège Rouyn-Noranda, CA- } \\
\text { QC J9X 5E5, Canada }\end{array}$ \\
\hline WA Ebook Library & Thư viện & Australia & OCLC \\
\hline
\end{tabular}




\begin{tabular}{|c|c|c|c|}
\hline & công & & \\
\hline HSRC Library & $\begin{array}{l}\text { Thư viện } \\
\text { công }\end{array}$ & Nam Phi & OCLC \\
\hline $\begin{array}{l}\text { University of Alberta } \\
\text { Libraries }\end{array}$ & Đại học & Canada & $\begin{array}{l}\text { https://neos.library.ualberta.ca/uhtbin/ } \\
\text { cgisirsi/x/0/0/57/5?user_id=WUAARCHIVE\&se } \\
\text { archdata1=3110686082 }\end{array}$ \\
\hline $\begin{array}{l}\text { New York University } \\
\text { Library }\end{array}$ & Đại học & $\begin{array}{l}\text { Mỹ, New } \\
\text { York }\end{array}$ & $\begin{array}{l}\text { https://bobcat.library.nyu.edu/permalink/f/ci13e } \\
\text { u/nyu_aleph007494635 }\end{array}$ \\
\hline Pamukkale University & Đại học & Thổ Nhĩ Ky & http://tarama.pau.edu.tr/ \\
\hline $\begin{array}{l}\text { Rijksuniversiteit } \\
\text { Groningen, } \\
\text { Universiteitsbibliotheek }\end{array}$ & Đại học & Hà Lan & OCLC \\
\hline Koninklijke Bibliotheek & $\begin{array}{l}\text { Thư viện } \\
\text { quốc gia }\end{array}$ & $\begin{array}{l}\text { Hà Lan, Den } \\
\text { Hague }\end{array}$ & OCLC \\
\hline $\begin{array}{l}\text { Universiteit van Tilburg, } \\
\text { Bibliotheek }\end{array}$ & Đại học & Hà Lan & OCLC \\
\hline $\begin{array}{l}\text { Vancouver School of } \\
\text { Theology Library. H.R. } \\
\text { MacMillan Library }\end{array}$ & Đại học & $\begin{array}{l}\text { Canada, } \\
\text { Vancouver }\end{array}$ & OCLC \\
\hline $\begin{array}{l}\text { National Library of } \\
\text { Sweden (LIBRIS) }\end{array}$ & $\begin{array}{l}\text { Thư viện } \\
\text { quốc gia }\end{array}$ & $\begin{array}{l}\text { Thụy Điển, } \\
\text { Stockholm }\end{array}$ & http://libris.kb.se/bib/bnbj27nx8b22tvbz \\
\hline $\begin{array}{l}\text { Uppsala } \\
\text { universitetsbibliotek, } \\
\text { Digitala biblioteket }\end{array}$ & Đại học & $\begin{array}{l}\text { Thụy Điển, } \\
\text { Uppsala }\end{array}$ & $\begin{array}{l}\text { http://ezproxy.its.uu.se/login?url=https://www.d } \\
\text { egruyter.com/openurl?genre=book\&isbn=9783 } \\
110686081\end{array}$ \\
\hline $\begin{array}{l}\text { Stockholms } \\
\text { universitetsbibliotek, } \\
\text { Digitala resurser }\end{array}$ & Đại học & $\begin{array}{l}\text { Thụy Điển, } \\
\text { Stockholm }\end{array}$ & $\begin{array}{l}\text { http://link.sub.su.se/sfxsub?url_ver=Z39.88- } \\
\text { 2004\&ctx_ver=Z39.88-2004 }\end{array}$ \\
\hline $\begin{array}{l}\text { Kungliga Tekniska } \\
\text { högskolan (Học viện } \\
\text { Công nghệ Hoàng gia) }\end{array}$ & Đại học & $\begin{array}{l}\text { Thụy Điển, } \\
\text { Stockholm }\end{array}$ & $\begin{array}{l}\text { https://kth- } \\
\text { primo.hosted.exlibrisgroup.com/permalink/f/qr } \\
\text { a184/46KTH_ALMA_DS51171165260002456 }\end{array}$ \\
\hline $\begin{array}{l}\text { Chalmers tekniska } \\
\text { högskola }\end{array}$ & Đại học & $\begin{array}{l}\text { Thụy Điển, } \\
\text { Göteborg }\end{array}$ & $\begin{array}{l}\text { http://search.ebscohost.com/login.aspx?direct } \\
\text { =true\&AuthType=sso\&db=edsebk\&AN=22830 } \\
\text { 58\&site=eds- } \\
\text { live\&scope=site\&custid=s3911979\&authtype= } \\
\text { sso\&group=main\&profile=eds }\end{array}$ \\
\hline
\end{tabular}

Cũng vào dịp cuối năm, cuốn sách, cùng với tên Phenikaa University, đã được giới thiệu tới độc giả của University World News (UWN), ngày 21 tháng 11, qua bài viết [2].

UWN xuất bản các báo cáo, bài phân tích và tóm lược các hoạt động, sự kiện về giáo dục đại học toàn cầu. Tờ báo có uy tín cao trong ngành nghề giáo dục đại học, và là mạng lưới, diễn đàn của rất nhiều chuyên gia đầu ngành. Những đơn vị bảo trợ quốc tế của UWN bao gồm các tên tuổi nhu: Ford Foundation, Carnegie Foundation. UWN đã từng đóng vai trò bảo trợ truyền thông cho các sự kiện toàn cầu như: UNESCO World Conference on Higher Education (2009), OECD Institutional Management in Higher Education Conference (Paris, 2010) hay Going Global 2016 của British Council. _ 


\section{References}

Quan-Hoang Vuong, and Trung Tran. (2019). The Vietnamese Social Sciences at a Fork in the Road. Warsaw, Poland: De Gruyter.

Quan-Hoang Vuong, and Hiep Pham. (2020). Accelerating social sciences reach a fork in the road. University World News (21 Nov. 2020).

https://www.universityworldnews.com/post.php?story=20201118123527565 